\title{
La mente del universo y la causalidad
}

\section{The Mind of the Universe and Causality}

\author{
RUBÉN PEREDA \\ Universidad de Navarra \\ ruben.pereda@unav.es
}

Resumen. En La mente del universo Mariano Artigas presenta un puente para conectar la ciencia y la teología. Una de las conexiones que se establecen entre ambas áreas del conocimiento pasa por la filosofía de la naturaleza, en concreto por el estudio de la causalidad; de hecho, en La mente del universo pueden encontrarse modos de entender y exponer la doctrina aristotélico-tomista de la causalidad que permiten, por un lado, la conexión entre ciencia y teología y, por otro, una mayor profundización en la comprensión filosófica del mundo natural.

Parablas clave: filosofía de la naturaleza; causa material; causa formal; causa eficiente; causa final; metafísica.

\begin{abstract}
In The Mind of the Universe Mariano Artigas builds a bridge connecting science and theology. One of the connections he establishes between the two areas of knowledge goes through the philosophy of nature, specifically through the study of causality; in fact, in The Mind of the Universe can be found ways to understand and to expose the Aristotelian-Thomistic doctrine of causality that allow, on the one hand, the connection between science and theology and, on the other hand, going deeper into the philosophical understanding of the natural world.
\end{abstract}

Keywords: Philosophy of Nature; Material Cause; Formal Cause; Efficient Cause; Final Cause; Metaphysics. 
El título de este artículo alude directamente a su fuente principal: el libro $L a$ mente del universo, de Mariano Artigas (2002). Como él mismo señala en la introducción, se recogen en este libro las ideas maduradas durante al menos diez años, "cuya finalidad es construir un puente que conecte la ciencia y la teología” (Artigas 2002, 18). El puente construido tiene diferentes pilares que lo sustentan eficazmente y que permiten, al mismo tiempo, diversas formas de atravesarlo. Mi intención es tratar solo una de estas formas de atravesar este puente: el camino de la causa.

La definición de causa que emplearé es la desarrollada por Antonio Millán-Puelles (2002, 77): “el principio real y positivo del que algo procede con dependencia en el ser”. Esta definición está cargada de contenido metafísico cuyo estudio no compete a estas páginas: baste señalar que considero que es una definición que recoge perfectamente el sentido aristotélico de causa. Por otro lado, en esta investigación me limitaré a identificar si en $L a$ mente del universo hay algún término que pueda incluirse en la definición de causa adoptada. Como curiosidad, se puede subrayar que en el "Índice de materias" términos como causa o causalidad brillan por su ausencia (Artigas 2002, 461-465). Si adoptamos los sentidos de causa aristotélicos (material, formal, eficiente y final) solo dos aparecen citados de una forma casi explícita en el "Índice de materias": materia y finalidad, y el primero de ellos con una referencia escueta. El segundo, sin embargo (la finalidad y la teleología) ocupa un lugar muy destacado.

En este sentido, cabría concluir que Artigas construye el puente que ha de conectar la ciencia y la teología sirviéndose únicamente de la causa final, por lo que se refiere al interés de este trabajo. No obstante esta apariencia, creo que se puede mantener que las cuatro causas aristotélicas están presentes. Y no solo eso: pueden encontrarse razones más que suficientes para defender la vigencia de los cuatro sentidos aristotélicos de causa en los avances de la ciencia y de la filosofía de la ciencia que Artigas tiene presentes a la hora de elaborar sus argumentos. Empezaré con los dos sentidos que aparecen en el "Índice de materias" (apartados 1. Materia y 2. Finalidad), para considerar posteriormente los otros dos sentidos (apartados 3. Forma y 4. Eficiencia). El tratamiento de estos apartados es desigual, como es 
desigual la importancia que da Artigas a cada uno de ellos en La mente del universo, donde la finalidad ocupa el lugar más destacado.

\section{Materia}

Mariano Artigas sostiene que la cosmovisión contemporánea implica un cambio en el modo de entender la materia, pasando de "algo pasivo e inerte" a "algo que posee un dinamismo interno en todos los niveles naturales" (Artigas 2002, 138). Este cambio es muy relevante, en la medida en que se abandona una comprensión de la materia "como una entidad extensa, homogénea, impenetrable e inerte" (Arana2010, 719). Frente a esta postura, el dinamismo que presenta Artigas permite un concepto de materia que no se cierra en una serie determinada de notas. En este sentido, Juan Arana ha señalado que el concepto científico actual de materia sería el del "conjunto de todas las determinaciones empíricas actuales y potenciales de la realidad espacio-temporal, susceptibles de ser encuadradas en el marco de los diferentes tipos de leyes (deterministas o probabilistas) consideradas por las ciencias positivas" (Arana2010, 720). Este concepto permite una noción de materia sumamente plástica, en la medida en que se limita a advertir su lugar dentro de la consideración científica.

Desde el punto de vista metafísico, el concepto de materia como poseedora de un dinamismo interno tiene gran relevancia. En la tradición aristotélica, si bien hay diversidad de interpretaciones, cabe una comprensión de la materia como causa plástica que puede recibir todo tipo de determinaciones. Andrew Pinsent, por ejemplo, caracteriza la materia como “principio de continuidad entre estados transformados" (Pinsent 2013, 358). Un rasgo propio de este principio de continuidad es que "no puede darse una respuesta a la pregunta por qué es este principio, al menos si se requiere una respuesta según el modo acostumbrado de los objetos matemáticos, como un valor numérico, una posición en el espacio, o alguna forma geométrica determinada" (Pinsent 2013, 357-358). Esta forma de entender la materia es muy similar a la que presenta Aristóteles: "entiendo por materia la que de suyo ni es algo ni es cantidad ni ninguna otra cosa de las que determinan al ente. Pues es algo de lo que se predica cada una de estas cosas y cuyo ser es 
diverso del de cada una de las categorías [...]; de suerte que lo último no es, de suyo, ni algo ni cuanto ni ninguna otra cosa; ni tampoco sus negaciones, pues también estas serían accidentales" (Aristóteles 2013, 328 [1029a 20-26]).

Este texto aristotélico presenta la materia precisamente como un principio de lo real que permanece más allá de los cambios accidentales; dicho de otro modo, la materia aparece más como apertura a diferentes determinaciones. Esta apertura de la causa material es la condición de posibilidad del dinamismo que caracteriza a la cosmovisión actual del mundo material. En este sentido, el dinamismo interno del que habla Artigas tiene sus raíces en la estructura metafísica de la realidad.

En consecuencia, hay una concordancia entre la visión de lo material como una realidad dinámica en todos sus niveles y la visión metafísica de la materia como una causa, es decir, como un "principio real y positivo del que algo procede con dependencia en el ser”. Cabría apuntar que el dinamismo de lo material es consecuencia, en concreto, del carácter de principio de la causa material. Este principio se caracteriza por su apertura para ser completado por las otras causas. En este sentido, si lo que existe actualmente no tuviese una dependencia real de la materia, el dinamismo del mundo natural sería imposible, ya que carecería de un sustrato totalmente plástico, como es la causa material.

Es evidente que las notas de la materia que se apuntan aquí necesitan una mayor investigación. Parte de la dificultad para desarrollar una explicación de la materia tiene que ver con lo que apunta Thomas Ainsworth (2016): "la materia ha de entenderse realmente como una noción relativa -es siempre la materia de algo". Esta misma expresión puede entenderse de muchos modos: en su sentido más básico, sirva para indicar que la noción de materia ha de estudiarse en relación con la noción de forma. Como ya se ha señalado, la noción de forma se estudiará en el apartado 3.

\section{Finalidad}

En cierto sentido puede afirmarse que uno de los grandes temas de La mente del universo es la finalidad; este lugar destacado no se debe únicamente al 
espacio que ocupa en el libro. Se trata más bien de una cuestión cualitativa, ya que la finalidad desempeña un papel decisivo en el razonamiento de Artigas (2000, 19): “deseo mostrar que la cosmovisión actual proporciona una base muy adecuada para una perspectiva que incluye la finalidad". La consideración de la finalidad - tratada como teleología - es fundamental para comprender el intento de construir puentes entre ciencia y teología que ofrece Artigas. Son bien conocidos los obstáculos a los que se enfrentará quien quiera emplear nociones finalistas en el ámbito científico; sin embargo, la propuesta de Artigas es que precisamente en el ámbito científico surgen las mejores ayudas para la teleología.

Para Mariano Artigas la teleología es un hecho corroborado desde la perspectiva de la cosmovisión actual. Es más, afirma que "el progreso de la ciencia muestra claramente que la finalidad natural es una dimensión real de la naturaleza” $(2000,184)$. Ahora bien, ¿qué es lo más característico de la finalidad?

Las dimensiones teleológicas se refieren, de un modo u otro, a la "direccionalidad”. En efecto, la direccionalidad indica que existen tendencias hacia objetivos, lo cual es el sello distintivo de la teleología natural. Cuando diferentes componentes de la naturaleza cooperan en la producción de un resultado unitario, se trata de una direccionalidad que puede denominarse “cooperatividad” (Artigas 2000, 187).

Lo característico de la finalidad, por tanto, es la direccionalidad: la orientación de lo real hacia un objetivo. Ahora bien, siguiendo a Artigas cabe distinguir entre la orientación y el objetivo. Si se analiza con detalle su propuesta, se puede apreciar que el amplio campo semántico de la finalidad - "holismo, funcionalidad, morfogénesis, información, tendencias, y sinergia o cooperatividad" (Artigas 2000, 182) - que forma parte del acervo común de la ciencia contemporánea refleja la variedad de problemas que pueden tratarse en términos teleológicos. Artigas (2000, 182-184) distingue cuatro niveles que se suceden, siendo cada uno de ellos supuesto del siguiente:

1. Fin de un proceso: el sentido más neutral y cronológico, se refiere al momento en el que un proceso acaba y da paso a otro. 
2. Meta de una tendencia: la carga finalista de este sentido es más fuerte, pues supone que el desarrollo de los procesos reales está determinada en una dirección concreta. Aparecen aquí dos problemas: la determinación de la existencia de tendencias y su explicación.

3. Valor para un sujeto: en este sentido se cuestiona la conveniencia o inconveniencia de un determinado suceso para un determinado sujeto (o grupo de sujetos). Artigas subraya que "las discusiones sobre teleología se refieren, tarde o temprano, a valores” (Artigas 2000, 184).

4. Objetivo de un plan: el cuarto y último sentido presupone una inteligencia que organiza acciones, sucesos o eventos en función de un objetivo proyectado en el futuro.

A la luz de este esquema se puede ver que Artigas sostiene que hay dos tipos fundamentales de teleología: teleología pre-intencional (fines, metas y valores), y teleología intencional (objetivos). El primer tipo de teleología, con sus correspondientes subdivisiones, se corresponde con la orientación de lo real. El segundo tipo se corresponde con el objetivo al que se orienta lo real.

La orientación de lo real, según Artigas, es omnipresente: “toda la construcción de nuestro mundo es el resultado del despliegue de tendencias que en muchos casos colaboran para construir sistemas unitarios" (Artigas 2000, 187). Así, desde los componentes más elementales de nuestro mundo hasta los sistemas vivos más complejos hay un hilo conductor: las tendencias que guían todo el proceso. Estas tendencias, señala Artigas, no son un caso aislado: "cualquier parte del conocimiento científico puede ser interpretada como un caso particular de tendencias naturales: en efecto, cualquier avance científico nos ayuda a conocer cómo se despliega el dinamismo natural siguiendo canales privilegiados" (Artigas 2000, 187). En este sentido, el descubrimiento de tendencias -y los valores correspondientes, es decir, la conveniencia o inconveniencia de un determinado suceso para un determinado sujeto o grupo de sujetos- es una tarea propia de toda actividad científica. Otra cuestión es el objetivo (o los objetivos) a los que se orientan estas tendencias. 
El objetivo (la teleología intencional) es el aspecto más difícil de asumir del planteamiento de Artigas y el que, en última instancia, hace de la finalidad una cuestión disputada: las tendencias que se descubren en la realidad pueden explicarse de muchos modos-que, como veremos más adelante, se relacionan con el sentido de la información-; pero solo se pueden llamar en sentido propio causas finales si se sitúan en el contexto de un objetivo mayor que el conjunto que forman todas las tendencias.

Este objetivo, la causa final, no es objeto de investigación científica, no conduce necesariamente a un proceso evolutivo constante y exige la explicación en términos de causas eficientes, a las que todavía no hemos hecho referencia (Artigas 2000,194). Artigas adopta estos planteamientos negativos con la intención de responder a una visión crítica de la causa final dominante en el ámbito científico que tiende a calificar a la finalidad de inútil, imposible, incognoscible e ilegítima. Para responder a estos calificativos, Artigas señala que la cosmovisión actual, basada en la auto-organización de la naturaleza, no solo descubre tendencias ${ }^{1}$, siendo muy útil considerar la finalidad, sino que, mediante el recurso a la información, especialmente en el ámbito de la genética, se podría afirmar que el proceso depende -para ser el proceso concreto que se estudia- de un principio que todavía no se ha alcanzado, pero cuya influencia difícilmente se puede negar sin negar el proceso que se examina. Al mismo tiempo, el recurso a la finalidad está legitimado por la presencia de "la funcionalidad, la direccionalidad, la cooperatividad y todas las dimensiones teleológicas [...] siempre que exista una situación de organización estable” (Artigas 2000, 206).

En conclusión, Artigas concibe la finalidad como la característica que guía la auto-organización del mundo. Se encuentra presente en toda la naturaleza, endiferentes niveles - fines, metas, valores y objetivos-que se interrelacionan entre sí.

\footnotetext{
1 “La auto-organización se refiere a aspectos holísticos, funcionales y direccionales de la naturaleza. Además, algunos de los progresos más relevantes en la ciencia contemporánea se refieren a la biología molecular, donde la funcionalidad, organización, direccionalidad y racionalidad son lo habitual" (Artigas 2000, 205).
} 
No obstante lo señalado, la teleología pre-intencional es una de las cuestiones más discutidas en la historia de la filosofía: en la modernidad existe cierto consenso acerca de su rechazo; una teleología pre-intencional sería contradictoria en la medida en que la teleología presupone intención; en consecuencia, solo cabría una teleología intencional en el mundo natural, postura que se descalifica inmediatamente por el antropomorfismo implícito. Sin embargo, posturas más clásicas, anteriores al desarrollo de la ciencia moderna, mantienen la existencia de una teleología pre-intencional. En este sentido, ha de distinguirse muy bien el concepto clásico de finalidad de los ejemplos usados para ilustrarla y de las interpretaciones que, al hilo de estos ejemplos, se han desarrollado a lo largo de la historia de la filosofía. Son bien conocidas las imágenes que utiliza Aristóteles para ilustrar la causa final: el propósito del escultor, la puntería del arquero... Ahora bien, una lectura excesivamente literal de estos ejemplos puede llevar al hilozoísmo, es decir, a la suposición de que la naturaleza está llena de seres conscientes que se mueven por objetivos: en otras palabras, el denostado antropomorfismo. Ya se ha visto que los objetivos, según Artigas, pertenecen únicamente al último nivel de la finalidad, y se encuentran en un grupo aparte, el de la teleología intencional.

En este sentido, es pertinente un estudio detallado del significado del "deseo natural" aristotélico-tomista, que constituye una de las apuestas más fuertes por una teleología pre-intencional. ¿Cabe afirmar que en la naturaleza se da esta inclinación hacia un fin? Sarah Broadie analizó detenidamente el ejemplo del artesano adoptado por Aristóteles para concluir que no implica antropomorfizar la naturaleza. En el análisis que ofrece advierte que la relación entre la habilidad del artesano y el objeto conseguido por el ejercicio de esa habilidad está excluido el propósito: dicho de otro modo, el aspecto que quiere destacar Aristóteles con el ejemplo del artesano es la relación que existe entre la técnica y el resultado del ejercicio de la técnica, abstrayendo el hecho de que se trate de un agente intencional y que, por tanto, de que en la adquisición de la técnica intervenga necesariamente la intencionalidad. En este sentido, Aristóteles, con su ejemplo, pretende subrayar que la capacidad alcanza su fin de un modo que puede asimilarse 
a lo pre-intencional, que es independiente del propósito que tenga el alfarero para hacer el jarrón, o de las horas de trabajo que ha tenido que emplear para alcanzar dicha habilidad (Broadie 1987, 42-44).

Obviamente, estaexplicación no es exhaustiva y requeriría un desarrollo más extenso; sin embargo, por otro lado, abre una posibilidad para admitir sentidos de "teleología” que sean pre-intencionales. De este modo, la propuesta de Artigas podría usarse para aclarar aspectos que habían quedado ocultos en la tradición aristotélica.

\section{Forma}

Ya he señalado que el término forma - de la causalidad formal- no aparece en el "Índice de materias" de La mente del universo. Sin embargo, esta ausencia del término exacto no implica que no se emplee la noción de forma: en concreto, siguiendo una indicación de G. Tanzella-Nitti en la III Lección conmemorativa "Mariano Artigas", puede vincularse la noción de forma a la de información (Tanzella-Nitti 2016, 18). Esta identificación afecta a uno de los conceptos fundamentales de la ciencia contemporánea, que merece un tratamiento más profundo del que se brindará en estas páginas. No obstante, en La mente del universo se encuentran elementos suficientes para establecer un punto de partida para la investigación.

Artigas se sirve del ejemplo de la comunicación celular descrita por Alfred G. Gilman para ilustrar lo que entiende por información y el papel que juega en la cosmovisión actual (Linder y Gilman 1992)². Señala explícitamente que a pesar de su origen en la biología -y más concretamente en la genética - "este concepto [información] puede ser fácilmente extendido a los seres no vivientes en la medida en que también ellos contienen todo un conjunto de potencialidades que se despliegan de modos bien definidos de acuerdo con las circunstancias en cada caso concreto" (Artigas 2000, 147). En esta primera observación se pueden destacar varios elementos:

2 Artigas se sirve del siguiente trabajo de Maurine E. Linder y Alfred G. Gilman, "G Proteins”, Scientific American 267/1 (1992): 36-46. 
en primer lugar, la información se refiere a las potencialidades del ser en cuestión. Estas potencialidades, en segundo lugar, siguen un desarrollo de un modo concreto, definido. Y en este desarrollo las circunstancias que rodean al ser en cuestión juegan un papel importante.

Dicho de otro modo, para Artigas la información "es almacenada, codificada y descodificada, transmitida e integrada” (Artigas 2000, 147). Según explica, la información natural se relaciona con el "conocimiento" que tienen los seres naturales -desde la más mínima partícula a la entidad más compleja- de qué deben hacer. Indica que es habitual emplear un lenguaje antropomórfico para describir la actividad de la naturaleza: este lenguaje, si bien es metafórico, "expresa hechos reales" (Artigas 2000, 149). Se encuentra, en consecuencia, una "racionalidad materializada" que "contiene instrucciones que se almacenan en estructuras materiales y se despliegan mediante procesos naturales” (Artigas 2000, 152).

La información, por tanto, puede verse como la pieza de la naturaleza que hace a lo existente ser lo que es: da lugar a las relaciones necesarias entre los elementos de un ser para que conserve (y, si es el caso, desarrolle) su estructura. Podría decirse que la información es un elemento real de los seres naturales que les hace tener un modo de ser concreto.

Uno de los más destacados estudiosos de la forma dentro de la tradición aristotélico-tomista es Lawrence Dewan. En sus investigaciones ha destacado que la forma es "por lo que” la materia llega a ser un ente. En esta línea, subraya que se puede distinguir entre "la forma, el principio físico, y la especie, el efecto de la forma que se encuentra en nuestra concepción intelectual de la cosa” (Dewan 2006, 153). Antes de continuar es importante advertir que el término información puede adoptar ambos sentidos: 1) aquello que se encuentra en la cosa haciendo que sea lo que es; y 2) el conocimiento que se puede obtener a partir de la cosa. El sentido que adopta Artigas, y que se explora en estas líneas, es el primero: forma, o información, como principio físico. El estudio de Dewan muestra que este sentido de la forma equivale a su función causal (Dewan 2006, 159), entendiendo causa como el "principio real y positivo del que algo procede con dependencia en el ser" al que se aludía al comienzo de estas páginas. 
En este caso, lo que procede es la realidad concreta. La forma, como causa, tiene una actividad constante: hace al ser natural que sea precisamente lo que es. Cabe una visión de la causalidad en sentido aristotélico que es completamente dinámica; es decir, que la realidad se concibe como un cambio continuo. En este sentido, la forma, o la información, contiene los principios que hacen al ser concreto existir y desarrollarse según sus potencialidades. Es importante distinguir este modo de causar del que tiene la teleología: podría decirse que la información señala el punto de partida -con todas las condiciones adyacentes-para alcanzar el fin del proceso.

\section{Eficiencia}

Hasta ahora se han encontrado señales - en algunos casos evidentes- de los sentidos de causalidad que se exploran en estas páginas: la materia tiene un epígrafe dedicado en exclusiva, la finalidad aparece por todo el libro, y la forma, a su modo, también. Sin embargo, si pretendemos encontrar la eficiencia, presumiblemente el sentido más común de causalidad y el que se puede aceptar con mayor facilidad, sorprende no encontrar ninguna referencia. ¿A qué se debe esta notable ausencia? Pueden darse varias opciones: en primer lugar, a que no es necesario hablar de lo que todo el mundo admite. Y, evidentemente, es fácilmente admisible que unos seres naturales tienen influencia sobre otros: las sucesivas gotas de agua desgastan la piedra sobre la que caen. Pero también podría argumentarse todo lo contrario: el uso del término causalidad, referido en exclusiva a la eficiencia, ha sido desterrado del lenguaje científico debido a la dificultad de saber exactamente a qué se refiere. Así, la eficiencia no comparece porque no hay un consenso al respecto.

Entre estos dos extremos caben todo tipo de interpretaciones: desde que no existe algo como la causa eficiente, hasta que es el único sentido admisible de causa. En estas líneas me limitaré a sugerir un sentido de eficiencia que puede alinearse con los otros sentidos de causa que se han presentado. 
Los sentidos que se han explorado anteriormente son la materia, que se identifica con la plasticidad y el dinamismo que permite la continuidad de los procesos de la naturaleza, la finalidad, que se identifica - en sentido pre-intencional-con fines, tendencias y valores presentes en estos mismos procesos, y la forma, que se identifica con la información que guía el desarrollo de los procesos naturales. En este conjunto de factores que posibilitan los procesos falta uno fundamental: el vínculo entre los elementos que intervienen en el proceso.

La eficiencia cumple este papel de vínculo entre los elementos que intervienen en el proceso: puede explicarse como la influencia de la información sobre la realidad que rodea a un ser natural para poner en marcha el proceso hacia una meta. Para lograrlo puede necesitarse tanto un proceso "interno" del ser natural como uno "externo". Tanto uno como otro puede verse como una forma de eficiencia, es decir, como una relación con realidades ajenas a la unidad de información de que se trate en cada momento. Esta relación puede establecerse mediante diferentes transmisores de la información, que permiten a los seres naturales crear conexiones entre ellos y tener así una influencia mutua. Esta aproximación puede relacionarse con el sentido clásico de causa eficiente: "principio del que fluye primariamente cualquier acción que hace que algo sea, o que algo sea de algún modo”(Vanney 2010, 151). Si adoptamos esta definición de eficiencia, la transmisión de información necesaria para iniciar o mantener un proceso puede verse como el ejercicio básico de la causalidad eficiente.

Puesto en relación con el sentido de la finalidad que se ha presentado, el ejercicio de la eficiencia es el medio para alcanzar el fin, la meta o el valor al que se ordena el proceso. Si la información permite iniciar el proceso, al dar el punto de partida y las herramientas con que se podrá alcanzar, la finalidad indica el resultado que se obtendrá mediante el ejercicio de la eficiencia; en este sentido, la eficiencia se ordena a la finalidad al permitir que se alcance el resultado correspondiente al proceso que se desarrolla.

Por último, la eficiencia se beneficia de la plasticidad de lo real para mantener el continuo dinamismo que permite realizar los procesos que constituyen el mundo natural. En este sentido, la materia que se encuentra 
en el sustrato del mundo natural está bajo la constante influencia de la causa eficiente: se puede hablar, por tanto, de una situación de permanente actividad en la realidad natural, en la que la materia es, precisamente, el sustrato que permite todo proceso y, en cierto sentido, lo sufre.

\section{Reflexión final}

En las páginas precedentes se ha presentado el resultado de una lectura de La mente del universo que estaba guiada por una idea muy concreta: descubrir en la obra de Artigas las claves para comprender la estructura del mundo natural. Este criterio ha hecho que se dejen de lado aspectos muyvaliosos, sobre todo los que se refieren al papel del hombre en la ciencia. Igualmente, se ha dejado de lado la apertura a la trascendencia, que Artigas trata con sumo acierto a lo largo del libro. Sin embargo, el hecho de dejar estas cuestiones sin tratar ha permitido, en mi opinión, que se ponga de relieve un rasgo muy interesante de La mente del universo.

La visión que presenta Artigas es la de una realidad dinámica, en continuo cambio. Pero este dinamismo se sostiene en una estructura precisa que posibilita los procesos que, en todas las escalas, constituyen el núcleo del mundo natural. La identificación de los elementos fundamentales de esta estructura, el desvelamiento de sus conexiones y dependencias, la certeza de que es posible que aparezcan novedades en el curso de un proceso... son guías para alcanzar un conocimiento profundo del mundo natural. Precisamente en este conocimiento profundo se descubre una sintonía de fondo con aspectos de la filosofía de la naturaleza de corte aristotélico. Si bien es una sintonía que exige estudios más detallados, creo que es posible afirmar que La mente del universo proporciona algunas claves importantes para emprender la tarea de reconciliar la cosmovisión contemporánea con la filosofía aristotélica. De esta reconciliación se beneficiarían ambas ramas del saber y, sobre todo, se abrirían las puertas a un mejor conocimiento del mundo que nos rodea. 


\section{Referencias}

Ainsworth, Th. 2016. “Form vs. Matter.” En The Stanford Encyclopedia of Philosophy, (Spring 2016 Edition), editado por E. N. Zalta, http://plato.stanford.edu/archives/ spr2016/entries/form-matter/.

Arana, J. “Materia.” 2010. En Diccionario de Filosofía, editado por A. L. González, 713-720. Pamplona: Eunsa.

Aristóteles. 2013. Metafísica, traducido por V. García Yebra, 2a ed., Madrid: Gredos. Artigas, M. 2002. La mente del universo, $2^{\mathrm{a}}$ ed., Pamplona: Eunsa.

Broadie, S. 1987. “Nature, Craft and Phronesis in Aristotle.”Philosophical Topics 15/2:35-50.

Dewan, L. 2006. Form and Being. Studies in Thomistic Metaphysics. Washington: The Catholic University of America Press.

Linder, M. E., y Alfred G. 1992. “G Proteins.” Scientific American 267/1:36-46.

Millán-Puelles, A. 2002. Léxico filosófico, $2^{\text {a }}$ ed., Madrid: Rialp.

Pinsent, A. 2013. "Why matter matters to neo-Aristotelian teleology in mechanics." Anuario Filosófico 46/2:347-364.

Tanzella-Nitti, G. 2016. ¿Se puede hablar de Dios en el contexto de la ciencia contemporánea? Pamplona: Servicio de Publicaciones de la Universidad de Navarra.

Vanney, C. 2010. “Causa.” En Diccionario de Filosofía, editado por A. L. González, 150-154. Pamplona: Eunsa. 